\title{
A FLEXIBILIZAÇÃO DO PACTA SUNT SERVANDA NOS CONTRATOS BANCÁRIOS DIANTE DOS PRINCÍPIOS FOCADOS NO DIRIGISMO CONTRATUAL
}

\author{
Mariah Rausch Pereira' \\ Régis Schneider Ardenghi
}

Resumo: Este trabalho versa sobre a flexibilização do pacta sunt servanda nos contratos bancários diante do dirigismo contratual, representado pelos princípios da função social do contrato, princípio da boa-fé e teoria da imprevisão. A presente pesquisa, tem como principal objetivo analisar a importância da flexibilização do pacta sunt servanda nos contratos bancários frente a outros princípios protegidos pela jurisprudência pátria. Quanto à metodologia utilizada para desenvolver o estudo, definiu-se como de abordagem dedutiva e técnica de pesquisa bibliográfica. O trabalho está organizado da seguinte maneira: primeiro trata dos contratos bancários e, após, incursiona sobre os princípios contratuais e por fim, a flexibilização do pacta sunt servanda nos contratos bancários. Como resultado, observa-se na jurisprudência pesquisada que o principal motivo da flexibilização

1 É mestranda em Direito pela Universidade Federal de Santa Catarina (UFSC). Graduada em Direito pela Universidade do Sul de Santa Catarina (UNISUL). Pós-graduada em Direito Aplicado ela Escola Superior da Magistratura do Estado de Santa Catarina (ESMESC) em 2013. Pós-graduada em Direito Público pela Escola Superior da Magistratura do Estado de Santa Catarina (ESMESC) em 2012. Pós-graduanda em Direito Penal e Processo Penal pela Faculdade de Direito Damásio de Jesus. E-mail: mariahrausch@live.com

2 Mestre em Ciência Jurídica pela Universidade do Vale do Itajaí (Univali). Professor de Direito na Universidade do Sul de Santa Catarina. Professor da Escola Superior da Magistratura do Estado de Santa Catarina (ESMESC). E-mail: regisardenghi@ hotmail.com 
dos contratos bancários é a aplicação da teoria da imprevisão, além de se resguardar a função social do contrato e a boa-fé nos casos de revisão contratual.

Palavras-chaves: Contratos bancários. Direito contratual. Jurisprudência. Pacta Sunt Servanda.

\section{INTRODUÇÃO}

O tema objeto do presente artigo científico versa sobre os contratos bancários e a flexibilização do pacta sunt servanta diante do dirigismo contratual, representados pelos princípios da função social do contrato, da boa-fé e pela teoria da imprevisão.

Sobre os contratos bancários, pode-se dizer, primeiramente, que é um dos poucos institutos que sobreviveram ao transcorrer do tempo e se adaptaram às mais diversas sociedades, estruturas de governo, existindo desde a Antiguidade, passando pela Idade Média, transcorrendo o Comunismo e consolidando-se no mundo capitalista.

Porém, onde vai haver maior desenvolvimento da relação contratual é no período sob a égide do capitalismo que vivemos. Porém, é justamente agora que o contrato bancário passa a ser flexibilizado, quebrando-se a isonomia do pacta sunt servanda.

Essa constatação é, pois, o que deu ensejo ao desenvolvimento da presente pesquisa, que permitirá incursionar no direito estrangeiro para conhecer o contexto em que o instituto se desenvolveu e as modalidades contratuais atualmente existentes, e essenciais para a existência do mundo globalizado. Tudo isso evidencia a importância e a emergência de estudos acerca dos contratos bancários.

Como objetivo geral, este artigo pretende analisar os contratos bancários vigentes no ordenamento brasileiro atual. Para atingir esse fim, será necessário, especificamente: conhecer o panorama histórico em que se desenvolveu o direito contra- 
tual; examinar os contratos bancários e as suas modalidades; e averiguar a flexibilização do instituto pela jurisprudência brasileira.

\section{CONTRATO BANCÁRIO}

A vida cotidiana está dominada pelas instituições financeiras, seja para o recolhimento das economias seja para o levantamento de capitais. A principal função dessas instituições é dinamizar o crédito e, esse objetivo é alcançado por meio de várias operações, como o depósito, redesconto, empréstimo, abertura de crédito etc. E, todas as operações bancárias realizadas poderão ser consideradas como contratos, pois há um acordo entre as partes e cria obrigações entre elas (DINIZ, 2012).

Compreende-se como atividade bancária o exercício das funções básicas das entidades que compõem o Sistema Financeiro Nacional. Constitui-se pelas funções básicas como a de coleta e intermediação ou a aplicação de recursos financeiros, próprios ou de terceiros. Essas funções podem ser exercidas em moeda nacional ou moeda estrangeira. Outras grandes atividades compreendidas nas funções das instituições bancárias englobam a captação de recursos e a concessão de crédito, que fazem com que o mesmo circule (RIZZARDO, 2006).

Também compreende, em outras atividades desempenhadas pelos bancos, certos tipos de investimentos: o arrendamento mercantil (ou leasing), a cobrança de crédito de terceiros, o repasse de valores, o depósito de bens. Além dessas, há as operações acessórias, que visam facilitar a vida da clientela bancárias, tais como a custódia de valores e o aluguel de cofres (DINIZ, 2012).

Arnaldo Rizzardo (2006) dispõe sobre quem pode exercer a atividade bancária:

Para exercer atividade bancária, indispensável o preenchimento de uma série de requisitos, dentre os quais a autorização governamental, expedida 
pelo Banco Central do Brasil, autarquia da União integrante do Sistema Financeiro Nacional, com inúmeras funções, dentre as quais as de emitir moeda, executar os serviços do meio circulante, controlar o capital estrangeiro, realizar operações de redesconto e empréstimos a instituições financeiras.

Define-se banco como a empresa que, com fundos próprios ou de terceiros, faz da negociação de crédito a sua atividade principal. Corresponde à espécie do gênero da instituição financeira. Esta aparece conceituada no artigo 17 da Lei ${ }^{\circ}$ 4.595, de 31.12.1964: 'A pessoa jurídica pública ou privada que tenha como atividade principal ou acessória a coleta, intermediação ou aplicação de recursos financeiros próprios ou de terceiros, em moeda nacional ou estrangeira, e a custódia de valor de propriedade de terceiros'.

Assim, para atuar no Brasil como instituição financeira e execer atividades bancárias é necessária a autorização do Banco Central, caso a empresa seja nacional, e decreto presidencial, para empresas estrangeiras (RIZZARDO, 2006).

As atividades bancárias podem ser dividas, conforme Miranda (2009), em típicas e atípicas:

As operações bancárias podem ser típicas, quando relacionadas com o crédito e o investimento de recursos, e atípicas, quando relacionadas com serviços secundários prestados aos clientes, como exemplo: locação de cofres e custódia de valores, e contas para depósitos judiciais. As operações bancárias típicas podem ser passivas, quando o banco se torna devedor, e ativas, quando o banco se torna credor.

Há, ainda, uma terceira classe de contratos bancários, a qual não é muito considerada pelos doutrinadores: a classe mista. Esta classe envolve uma mistura entre contratos típicos e atípicos, pois as operações envolvem créditos e serviços, características próprias das duas divisões usuais (LUZ, 1996). 
As peculiaridades dos contratos bancários justificam que eles possuam uma disciplina diferenciada. Como Orlando Gomes (2007) observa: "Os esquemas contratuais comuns, quando inseridos na atividade própria dos bancos, sofrem modificações sob o aspecto técnico, que determinam alterações em sua disciplina."

Todas essas relações jurídicas advindas das operações das instituições bancárias, não estão reguladas especificamente pelo Código Civil de 2002 (RIZZARDO, 2006).

Os contratos bancários e suas inúmeras operações são disciplinados em legislação específica que tem como principal objetivo proteger as partes e resguardar a política monetária nacional (GONÇALVES, 2010).

Resume-se, assim, que as atividade desempenhadas pelas instituições bancárias são muito utilizadas na vida cotidiana das pessoas e, embora largamente difundidas, não são resguardadas por lei própria ou amparadas pelo Código Civil 2002.

\subsection{Conceito de contrato bancário}

A designação genericamente utilizada para o negócio celebrado entre uma instituição bancária - ou financeira, ou equiparado por lei - e pessoa física ou jurídica é o contrato bancário (LISBOA, 2005).

Dorneller (apud DALLAGNOL, 2002) define contrato bancário como: "[...] negócio jurídico 'concluído por um Banco no desenvolvimento de sua atividade profissional e para a consecução de seus próprios fins econômicos." Assim, o autor adota um critério subjetivo como norteador para a sua definição, incluindo as atividades de prestação de serviços bancários no seu conceito.

Arnold Wald (2004, p. 653) conceitua:

Contratos bancários é denominação que se dá a um grupo de contratos em que uma das partes é um banco ou uma instituição financeira. São 
contratos de entidades que neles se especializaram, embora, em tese, possam ser realizados por quaisquer pessoas. Na prática e de acordo com a lei, só instituições bancarias e assemelhadas é que realizam habitualmente tais contratos com seus clientes.

Maria Helena Diniz (2012) dispõe que os contratos bancários são negócios jurídicos em que uma das parte, obrigatoriamente, tem que ser empresa autorizada a realizar atividades próprias de banco. Não se pode ter um contrato bancário em que uma das partes não seja um banqueiro, mesmo que possua todos os outros elementos que assim o caracterizem.

Para Carlos Roberto Gonçalves (2010, p. 671):

A expressão contratos bancários é indicativa de um grupo de contratos em que uma das partes é um banco ou uma instituição financeira. Há, efetivamente, algumas figuras contratuais que são próprias da atividade bancária e merecem essa designação. São modalidades reservadas, por lei, às instituições bancárias e assemelhadas e seus clientes.

Assim, nota-se que a principal figura nos contratos bancários é a instituição financeira, ou banco, sem esse não é possível ter-se um contrato bancário ( MONTEIRO; MALUF; SILVA, 2012).

Diz-se que contrato bancário é aquele em que uma das partes é um banco e o objeto que vem a ser contratado é o crédito (RIZZARDO, 2006).

Classificam-se os contratos bancários como: reais (somente consolida com a entrega da coisa); onerosos (os dois contratantes tem ganhos); e bilaterais (sendo que para ser considerado como tal em um dos polos da relação jurídica tem que haver uma instituição financeira e no outro pode haver uma pessoa física ou uma pessoa jurídica) (MONTEIRO; MALUF; SILVA, 2012). 
Pode-se ainda dizer que o contrato bancário é uma espécie de contrato de adesão. Segundo Sérgio Carlos Covello (apud MONTEIRO; MALUF; SILVA, 2012):

No Brasil, como de resto na maioria dos países, a padronização dos contratos bancários deve-se não só às razões expostas, com a intervenção do Estado, por meio do Banco Central, na vida dos bancos. Com efeito, as circulares e resoluções do Banco Central fazem com que as operações bancárias sejam praticadas com uniformidade, chegando, muitas vezes, a determinar até a própria minuta do contrato. Assim, os formulários que servem de instrumento de contratação bancária distinguem-se pela identidade formal, pela predeterminação de suas cláusulas, e pela inflexibilidade e rigidez de seu esquema. $O$ resultado disto é que, no contrato bancário, o consentimento do cliente se manifesta mediante adesão ao esquema proposto pelo banco, esquema este em que o cliente fica praticamente obrigado a aceitar, visto que adotado por todos os bancos de maneira padronizada Por exigência prática, a contratação bancária, no decorrer dos tempos, passou a ser feita por meio de formulário com cláusulas gerais e uniformes para todos os contratos de igual natureza. Assim, as condições contratuais passaram a ser previamente fixadas pelo banco, de forma a não admitirem contrapropostas. Os contratos bancários enquadram-se, desta feita, no rol dos chamados contratos de adesão, pelos quais a participação de um dos sujeitos se dá pela aceitação in totum das condições prefixadas pela outra parte para constituir o conteúdo normativo-obrigacional da futura relação concreta. Digamos, ou adere às condições ou não contrata. Não pode, entretanto, modificá-las ou pretender discuti-las com o banco.

Os formulários passam a ser o instrumento de contratação bancária e suas cláusulas já estão prefixadas, sem a possibilidade de serem flexibilizadas pelo contratante. Ou ele aceita da forma 
em que o banco lhe impõe, ou não haverá contrato entre as partes. Desta feita, os contratos bancários ficam caracterizados como contratos de adesão.

\section{FLEXIBILIZAÇÃO DO PACTA SUNT SERVANDA NOS CONTRATOS BANCÁRIOS DIANTE DOS PRINCÍPIOS FOCADOS NO DIRIGISMO CONTRATUAL}

A base teórica dos contratos inspirou-se no liberalismo econômico do século XIX, em que o objetivo era a circulação de riquezas. Neste contexto os indivíduos estariam livres para contratar, somente tendo que observar o que os vinculava, o conteúdo fixado pelo contrato, pelo princípio da pacta sunt servanda (LISBOA, 2005).

Com o fim da Guerra Fria , no século XX, e com o surgimento da nova ordem mundial, o contexto jurídico passa a ser permeado de novas ideias. As ideias liberais, tão exploradas no século XIX, sofrem uma hipotrofia devido ao novo sistema jurídico. $\mathrm{O}$ Estado passa a intervir nos contratos por meio de normas de ordem pública e de interesse social (LISBOA,2005)

$\mathrm{Na}$ concepção mais pura, o contrato deve permanecer incólume, inalterável, imutável em seu conteúdo e disposições por vontade unilateral de um dos contratantes. Isso decorre do tradicional princípio do pacta sunt servanda (VENOSA, 2012). Em regra, as partes tem plena liberdade para contratar, observando o princípio da autonomia da vontade, que deve sempre ser respeitada (MONTEIRO; MALUF; SILVA, 2012).

Porém, a liberdade de contratar extrapolou os limites aceitáveis, necessitando que o Estado intervisse na ordem econômica com o objetivo de restabelecer o equilíbrio das relações contratuais. Para atingir esse fim, passou a editar normas jurídicas de ordem pública, de natureza cogente, isto é, normas que não podem ser afastadas das relações jurídicas mesmo pela vontade expressa das partes (LISBOA, 2005). 
Por essa razão, o contrato adquiriu uma nova concepção, novas funções, por exigência da sociedade e do Estado moderno. Devido a essas novas exigências, o até então imutável pacta sunt servanda, em situações excepcionais, passa a ser flexibilizado por algumas causas, em decorrência do dirigismo contratual, tais quais, a boa-fé, a função social e a cláusula da onerosidade excessiva, conforme a doutrina e a jurisprudência tem aceito. (VENOSA, 2012). Princípios esses previstos no Código Civil de 2002, nos artigos 421, 422, 317 e 478.

Desta feita, os contratos bancários são especialmente atingidos, pois as instituições financeiras não podem mais avençar taxas de juros superiores a doze por cento ao ano, não podem convencionar juros sobre juros, entre outros, por determinações expressas do Estado (MONTEIRO; MALUF; SILVA, 2012).

Mesmo que o dirigimos contratual imponha alguns limites, o que as partes acordam, estipulam e aceitam, deve ser fielmente cumprido, de acordo com o princípio da pacta sunt servanda, sob pena de execução patrimonial contra o contratante inadimplente. Somente será possível derrogar essa regra caso ocorra a hipótese de caso fortuito ou força maior (art. 393, parágrafo único do $\mathrm{CC})^{3}$. Não sendo esses casos, o contrato terá que ser cumprido do modo em que foi pactuado (MONTEIRO; MALUF; SILVA, 2012).

Ainda, sobre o assunto, menciona Theodoro Júnior ( 2004, p. 06):

É inegável, nos temos atuais, que os contratos, de acordo com a visão social do Estado Democrático de direito, hão de submeter-se ao intervencionismo estatal manejado com o propósito de superar o individualismo egoístico e buscar a implantação de uma sociedade presidida pelo bem-estar e sob "efetiva prevalência da garantia jurídica dos direitos humanos.

3 Art. 393 CC. "O devedor não responde pelos prejuízos resultantes de caso fortuito ou força maior, se expressamente não se houver por eles responsabilizado.Parágrafo único. O caso fortuito ou de força maior verifica-se no fato necessário, cujos efeitos não era possível evitar ou impedir" (BRASIL, 2013a). 
O direito contratual não é mais conduzido somente pela força obrigatória dos contratos mas, também, pelo dirigismo estatal, sendo que seus princípios estão relativizados pelo princípio da boa fé, princípio da função social do contrato e pelo princípio da onerosidade excessiva (rebus sic stantibus) (BANDEIRA DE MELLO, 2005).

Assim, passa-se a ter uma autonomia relativa, tendo que se observar as restrições impostas por lei. Deve ser observado, também, pela supremacia da ordem pública, a moral e os bons costumes (MONTEIRO; MALUF, SILVA, 2012).

Dentro desse contexto, o que se busca é a função social do contrato. Pode-se afirmar, que esse princípio foi insculpida como cláusula geral do CC, no art. 4214. Essa função social referida na lei é uma limitação da liberdade de contratar. Tanto é verdade que se o contrato não atender com a função social ele será nulo por contrariar uma norma de ordem pública (art. 2.035 CC) $)^{5}$ (COELHO, 2010).

Observa-se que a função social do contrato prestigia interesses maiores do que os contratantes. Assim, não atenderá a função social os contratos cuja execução possa sacrificar, comprometer, ou lesar, de qualquer modo, interesses metaindividuais (COELHO, 2010).

A consequência para não observância da cláusula geral da função social do contrato é a nulidade do negócio jurídico e a responsabilidade dos contratantes pela indenização dos prejuízos provocados. É uma nulidade imposta por lei, sem afastar a obrigação de indenizar, para que a ofensa à norma de ordem pública seja reprimida por completo. Mais uma vez a autonomia de se contratar é flexibilizada (COELHO, 2010).

4 Art. 421 CC. "A liberdade de contratar será exercida em razão e nos limites da função social do contrato" (BRASIL, 2013a).

5 Art. 2.035 CC. "A validade dos negócios e demais atos jurídicos, constituídos antes da entrada em vigor deste Código, obedece ao disposto nas leis anteriores, referidas no art. 2.045, mas os seus efeitos, produzidos após a vigência deste Código, aos preceitos dele se subordinam, salvo se houver sido prevista pelas partes determinada forma de execução" (BRASIL, 2013a). 
Fábio Ulhoa Coelho (2010, p. 52) ensina que:

Cumpre sua função social o contrato que não sacrifica, compromete ou lesa interesses metaindividuais (públicos, difusos ou coletivos) acerca dos quais não têm os contratantes a disponibilidade. $\mathrm{O}$ contrato que descumpre a função social, prejudicando interesses dessa ordem, é nulo.

Destaca-se que o contrato, devido a função social prevista em lei, não é mais visto do prisma individualista mas em seu sentido social, ele tem que ser útil para a comunidade (MONTEIRO; MALUF; SILVA, 2012).

Do dirigismo contratual e da função social do contrato decorre o princípio da boa-fé, outra causa que enseja a flexibilização do pacta sunt servanda. Agir de boa-fé, significa que as partes possuem mútuo respeito, fornecem as informações de forma completa, verdadeira e claras, não enganam o outro não buscam esconder aspectos essenciais ao negócio. Age de má-fé quem descumpre com o dever geral de boa-fé ou desrespeitam o direito do outro contratante (COELHO, 2010).

Incorre em ato ilícito quem não age com a boa-fé, tanto na execução como na negociação do contrato, descumprindo com uma obrigação imposta por lei. Como qualquer outra ilicitude, as consequências do descumprimento do dever geral de boa-fé objetiva, geram o dever de indenizar pelos prejuízos que a parte vier a sofrer (LISBOA, 2005).

Fábio Ulhoa Coelho (2010, p. 48), escreve:

Em razão da cláusula da boa-fé objetiva, os contratantes devem-se, tanto nas negociações como na execução do contrato, mútuo respeito quanto aos direitos da outra parte. Condutas que denuncia, ou sugerem o desrespeito - como a ocultação de vícios da coisa - caracterizam a ausência de boa-fé. O descumprimento do dever geral de boa-fé objetiva implica, pela lei, apenas a responsabilidade civil do contratante faltoso, que deve indenizar todos os prejuízos sofridos pela parte cujos direitos desres- 
peitou. Não há previsão legal que fundamente a revisão ou resolução do contrato em virtude da má-fé do contratante.

O CC também previu, em seu art. $422^{6}$, a obrigação de probidade, além da prever a cláusula geral da boa-fé. A probidade pode ser compreendida como a honestidade, retidão e caráter, senso de justiça das partes. $\mathrm{O}$ contratante que age de acordo com a probidade respeita os direitos do outro, o não age com probidade falta com a honestidade. Mesmo que o código trata com outro denominação agir com probidade é agir com boa-fé (COELHO, 2010).

A consumação do intervencionismo do Estado nos contratos ocorre com o surgimentos das cláusulas abusivas. Quando o Estado (Poder Judiciário) verifica que a liberdade de se contratar e a autonomia da vontade das partes gerou um contrato desiquilibrado ele intervêm na relação, revendo as cláusulas abusivas e favorecendo a parte mais fraca, via de regra, o consumidor (MONTEIRO; MALUF; SILVA, 2012).

Cláudio Belmonte (2002, p.141), ao tratar de cláusula abusiva, explica:

Assim, o ponto fulcral da caracterização da abusividade consiste na existência de cláusulas que coloquem o consumidor em desvantagem contratual exagerada em relação ao fornecedor, independentemente de essa situação ter sido gerada em face do díspar poder econômico entre as partes, ou do uso de condições gerais, ou, ainda, pelo simples fato de se estar utilizando contratos por adesão.

A interferência estatal, porém, não é generalizada, atinge apenas relações onde verifica-se que a desigualdade, e que esta gera um enorme prejuízo para uma das partes. Destaca-se, entre as relações que mais sobrem interferência do Estado, o os contratos bancários (BELMONTE, 2002).

6 Art. 422 CC. "Os contratantes são obrigados a guardar, assim na conclusão do contrato, como em sua execução, os princípios de probidade e boa-fé" (BRASIL, 2013a). 
Percebe-se, ainda, a intervenção, nos contratos bancários, que possuem cláusulas abusivas, além das previstas no CC, as do art. 51 do $\mathrm{CDC}^{7}$. Diz-se isso pois somente uma das partes, a instituição bancária, redige o contrato, alterando-o livremente, fixando as cláusulas que melhor lhe convenha sem resguardar o direito da outra parte, o contratante, que somente anui com o que foi posto (COELHO, 2010).

Assim, tem-se que as cláusulas abusivas geralmente ocorrem nos contratos bancários de adesão. Isto ocorre pois uma das partes detém o privilégio da elaboração das cláusulas contratuais, o que gera uma maior possibilidade de incluir cláusulas

7 Art. 51 CDC: "São nulas de pleno direito, entre outras, as cláusulas contratuais relativas ao fornecimento de produtos e serviços que: I - impossibilitem, exonerem ou atenuem a responsabilidade do fornecedor por vícios de qualquer natureza dos produtos e serviços ou impliquem renúncia ou disposição de direitos. Nas relações de consumo entre o fornecedor e o consumidor pessoa jurídica, a indenização poderá ser limitada, em situações justificáveis; II - subtraiam ao consumidor a opção de reembolso da quantia já paga, nos casos previstos neste código; II I- transfiram responsabilidades a terceiros; IV - estabeleçam obrigações consideradas iníquas, abusivas, que coloquem o consumidor em desvantagem exagerada, ou sejam incompatíveis com a boa-fé ou a eqüidade; V - (Vetado); VI - estabeleçam inversão do ônus da prova em prejuízo do consumidor; VII - determinem a utilização compulsória de arbitragem; VIII - imponham representante para concluir ou realizar outro negócio jurídico pelo consumidor; IX - deixem ao fornecedor a opção de concluir ou não o contrato, embora obrigando o consumidor; $X$ - permitam ao fornecedor, direta ou indiretamente, variação do preço de maneira unilateral; $\mathrm{XI}$ autorizem o fornecedor a cancelar o contrato unilateralmente, sem que igual direito seja conferido ao consumidor; XII - obriguem o consumidor a ressarcir os custos de cobrança de sua obrigação, sem que igual direito lhe seja conferido contra o fornecedor; XIII - autorizem o fornecedor a modificar unilateralmente o conteúdo ou a qualidade do contrato, após sua celebração; XIV - infrinjam ou possibilitem a violação de normas ambientais; XV - estejam em desacordo com o sistema de proteção ao consumidor; XVI - possibilitem a renúncia do direito de indenização por benfeitorias necessárias. $\S 1^{\circ}$ Presume-se exagerada, entre outros casos, a vantagem que: I - ofende os princípios fundamentais do sistema jurídico a que pertence; II - restringe direitos ou obrigações fundamentais inerentes à natureza do contrato, de tal modo a ameaçar seu objeto ou equilíbrio contratual; III - se mostra excessivamente onerosa para o consumidor, considerando-se a natureza e conteúdo do contrato, o interesse das partes e outras circunstâncias peculiares ao caso. $\S 2^{\circ} \mathrm{A}$ nulidade de uma cláusula contratual abusiva não invalida o contrato, exceto quando de sua ausência, apesar dos esforços de integração, decorrer ônus excessivo a qualquer das partes. $\S 3^{\circ}$ (Vetado). $\S 4^{\circ} \mathrm{E}$ facultado a qualquer consumidor ou entidade que o represente requerer ao Ministério Público que ajuíze a competente ação para ser declarada a nulidade de cláusula contratual que contrarie o disposto neste código ou de qualquer forma não assegure o justo equilíbrio entre direitos e obrigações das partes. 
que sejam desfavoráveis ao aderente. Mesmo havendo negociação entre as partes, isto não garante que cláusulas abusivas não sejam inseridas no mesmo (MONTEIRO; MALUF; SILVA, 2012).

Nos contratos bancários observa-se que a instituição financeiras detém o privilégio de formular as cláusulas contratuais, não possibilitando à outra parte negociar os termos pactuados. Por essa razão, usualmente, o Estado é chamado a intervir nas relações para restabelecer o equilíbrio contratual, quebrando com a autonomia da vontade estabelecida pelo pacta sunt servanda (COELHO, 2010).

Pelo princípio da obrigatoriedade dos contratos (pacta sunt servanda), os contratos não podem ser violados se o acontecimento futuro era, ao tempo da contratação, perfeitamente previsível. $\mathrm{O}$ contrato sempre visa uma situação futura, desta forma, os contratantes tem que ter previsões de situações futuras. A imprevisão somente autorizará a rescisão do contrato quando fugir totalmente da possibilidade de previsão das partes (VENOSA, 2012).

De acordo com Sílvio de Salvo Venosa (2012, p. 479):

Desse modo, questões meramente subjetivas do contratante não podem nunca servir de pano de fundo para pretender uma revisão nos contratos. A imprevisão deve ser um fenômeno global, que atinja a sociedade em geral, ou um segmento palpável de toda essa sociedade. É a guerra, a revolução, o golpe de Estado, totalmente imprevistos.

Para que se possa resolver o contrato baseado na teoria da imprevisão é necessário que seja apurado as condições explicitadas no art. 478 do Código Civil de 2002 (BRASIL, 2013) a saber:

Art. 478. Nos contratos de execução continuada ou diferida, se a prestação de uma das partes se tornar excessivamente onerosa, com extrema vantagem para a outra, em virtude de acontecimentos extra- 
ordinários e imprevisíveis, poderá o devedor pedir a resolução do contrato. Os efeitos da sentença que a decretar retroagirão à data da citação.

Arnoldo Medeiros da Fonseca (apud Arnaldo Rizzardo, 2010, p. 140) destaca a necessidade de três elementos para que se configure a teoria da imprevisão:

a) a alteração radical no ambiente objetivo existente ao tempo da formação do contrato, decorrente de circunstâncias imprevistas e imprevisíveis;

b) onerosidade excessiva para o devedor e não compensada por outras vantagens auferidas anteriormente, ou ainda, esperáveis, diante dos termos do ajuste;

c) enriquecimento inesperado e injusto para o credor, como consequência direta da superveniência imprevista.

Para que o órgão judicial altere o contrato baseado na teoria da imprevisão deverá observar se os seguintes requisitos estão presentes: a) que o contrato comutativo de execução continuada esteja em vigência, uma vez que a teoria da imprevisão não se aplica aos contratos aleatórios; b) que as condições iniciais se alteraram de forma substancial no momento em que o contrato for executado; c) onerosidade excessiva para um dos contratantes e um benefício exagerado para o outro; d) que o acontecimento que deu causa a alteração da situação seja extraordinário e imprevisível às partes quando celebraram o contrato (DINIZ, 2012).

O devedor interessado deverá ingressar em juízo com o pedido de reconhecimento da teoria da imprevisão. Tal pedido deve conter o motivo para a liberação ou o pedido de redução das prestações no seu montante. Também o devedor que ingressa em juízo para a rescisão contratual não pode ter dado causa ao fato e além disso, estar adimplente com as prestações (VENOSA, 2012). 
Desta forma, o magistrado proferindo decisão favorável liberará o devedor das prestações avençadas e as depositadas durante o julgamento da lide ficarão sujeitas à modificação na execução da sentença. A sentença proferida produzirá efeitos ex tunc, retroagindo desde a data da citação (DINIZ, 2012).

Porém o artigo subsequente do Código Civil de 2002 possibilita que as partes, ao invés de resolverem o contrato, o modifiquem de forma equitativa uma vez que pode-se o mais (resolução) pode-se o menos (revisão) (GAGLIANO; PAMPLONA FILHO, 2009).

O art. 317 do CC (BRASIL, 2013) trata desta hipótese:

Art. 317. Quando, por motivos imprevisíveis, sobrevier desproporção manifesta entre o valor da prestação devida e o do momento de sua execução, poderá o juiz corrigi-lo, a pedido da parte, de modo que assegure, quanto possível, o valor real da prestação.

Assim, o contrato é colocado em atuais limites de cumprimento sem que se tenha a rescisão. A prestação se tornou excessiva, porém a sentença colocou limites aceitáveis de forma que possível de ser cumprido nos novos termos (VENOSA, 2012).

$O$ contrato visa uma situação futura, não podendo ser violado por causa de dificuldades previsíveis. Aduz Sílvio de Salvo Venosa (2012, p. 478): "A imprevisão que pode autorizar uma intervenção judicial na vontade contratual é somente aquela que revogue totalmente às possibilidades de previsibilidade".

Dessa forma, para ser considerada imprevisão, o fenômeno deve atingir a toda a sociedade ou grande parte dela, decorrente de uma circunstância global. Para serem consideradas como tais circunstância, elas podem ser enquadradas em dois grandes grupos: a) intrínsecas, b) extrínsecas. De acordo com Valério (2004, p. 37):

As primeiras se subdividem em dois outros grupos: teorias com base na vontade e teorias com base na prestação. Dentre as teorias com base na vontade 
estão: a teoria da pressuposição, a teoria da vontade marginal, a teoria da base do negócio, a teoria do erro, a teoria da situação extracontratual e a teoria do dever de esforço. Dentre as teorias com base na prestação estão a teoria do estado de necessidade e a teoria do equilíbrio das prestações. Já as extrínsecas se dividem em fundamento na moral, fundamento na boa-fé, fundamento na extrinsibilidade do fortuito, fundamento na socialização do Direito e fundamento na equidade e na justiça.

Assim, as circunstância capazes de atingirem os contratos, a tal ponto de ser invocada a cláusula rebus sic stantibus, tem que atingir a sociedade como um todo (VALÉRIO, 2004).

\subsection{Revisão contratual e análise jurisprudencial}

Com o advento dos contratos de adesão e o desequilíbrio que causaram nas relações de consumo, criou-se um dispositivo que possibilitou alguma proteção contra as disparidades e ensejou a maior aplicação de alguns princípios contratuais. Porém, deve-se considerar a extensão da disparidade ou do desequilíbrio do consumidor e se existem outras considerações que possam ser tomadas (MARQUES, 2011).

Por ser de teor subjetivo, o Código de Defesa do Consumidor (CDC) elenca, em seus arts. $6^{\circ}$, VII, e 84, a tutela jurisdicional que pode ser prestada ao consumidor. Com isso, confere-se aos juízes o poderia de decisão, quando suscitados, a respeito da matéria, atualizou procedimentos preexistente (como a ação civil pública); criou novos mecanismos (ação coletiva); inovou na sentença, sua liquidação e execução; dentre outros importantes provimentos à defesa do consumidor (ALMEIDA, 2009).

Diante disso, passa-se a ser notória a intervenção judicial e há uma maior adequação das cláusulas contratuais quando verificado o desequilibrio entre as partes na relação obrigacional.

No que diz respeito à aplicação do CDC aos contratos bancários, a matéria foi pacificada com o julgamento da Ação 
Direta de Inconstitucionalidade $\mathrm{n}^{\circ}$ 2.591/DF, incluindo na interpretação do $\operatorname{art.} 3^{\circ}, \S 2^{\circ}$, do CDC, as instituições bancarias que prestem os serviços de financiamento, de crédito e securitários (MARQUES, 2011).

E isso fica evidenciado em julgados dos tribunais pátrios. São vários os casos de revisões contratuais, numa clara flexibilização do pacta sunt servanda.

Para demonstrar, primeiro colaciona-se a emenda do Acórdão da apelação cível $n^{\circ}$ 2012.081040-8, do Tribunal de Justiça de Santa Catarina, sobre a problemática aqui abordada:

\begin{abstract}
APELAC̣ÃO CÍVEL. AC̣ÃO REVISIONAL. CONTRATO DE EMPRÉSTIMO. CÓDIGO DE DEFESA DO CONSUMIDOR. INCIDÊNCIA NAS RELAÇÕES ENVOLVENDO INSTITUIÇÕES FINANCEIRAS. SÚMULA 297 DO STJ. REVISÃO DE CLÁUSULAS CONTRATUAIS. POSSIBILIDADE. INTELIGÊNCIA DOS ARTIGOS 6, V, E 51, E SEUS \$\$, DO CDC e 421 e 422, DO CÓDIGO CIVIL.
\end{abstract}

"O Código de Defesa do Consumidor é aplicável às instituições financeiras” (Súmula 297, do STJ), pelo que, afetado ao consumidor o direito público subjetivo de obter da jurisdição "a modificação de cláusulas contratuais que estabeleçam prestações desproporcionais, ou sua revisão em razão de fatos supervenientes que as tornem excessivamente onerosas", bem como a declaração de nulidade das que se apresentem nulas de pleno direito, por abusividade, ou não assegurem o justo equilíbrio entre direitos e obrigações das partes, possível é a revisão dos contratos, visto a legislação consumerista ter relativizado o princípio pacta sunt servanda.

Essa possibilidade de revisão se insere nos princípios também consagrados pelo Código Civil vigente, de condicionar a liberdade de contratar "em razão e nos limites da função social do contrato”, obrigando que os contratantes guardem, "assim na conclusão do contrato, como em sua execução, os 
princípios de probidade e boa-fé" (arts. 421 e 422) (SANTA CATARINA, 2012).

No caso em tela, a autora ingressa com uma ação de revisão de contrato com o objetivo de examinar as cláusulas estipuladas no contrato de empréstimo consignado em folha de pagamento com a requerida (Banco $\mathrm{BMG} \mathrm{S} / \mathrm{A}$ ) e que fosse aplicado o Código de Defesa do Consumidor ao caso (CDC).

$\mathrm{O}$ juiz singular julgou parcialmente procedente o pedido formulado na exordial para: a) reconhecer a aplicação do CDC; b) aplicação do disposto no art. 359 do Código de Processo Civil, presumindo abusiva a cláusula que estabelece a taxa de juros remuneratórios; b.1) fixar a incidência dos juros remuneratórios em $12 \%$ ao ano conforme previsto no CC e no Código Tributário Brasileiro; b.2) vedar a capitalização mensal ou anual dos primeiros juros; b.3) vedar a cobrança da comissão de permanência para o período de inadimplência; c) limitar os encargos de inadimplência aos juros de mora, em 1\% ao mês; d) determinar a devolução à autora do que eventualmente foi pago à título de juros remuneratório em percentual superior a $12 \%$ ao ano, juros de capitalização, comissão de permanência e outros encargos; e) deferir a antecipação tutela; e.1) vedar a inscrição do nome da autora nos cadastros de inadimplentes; e.2) manter a decisão que deferiu a suspensão do desconto das prestações do financiamento diretamente da folha de pagamento da autora, até a liquidação da sentença; e.3) autorizar o depósito judicial das prestações do financiamento no valor incontroverso.

Resignada com a decisão, a instituição bancária ingressou com Apelação Cível, arguindo a impossibilidade da revisão das cláusulas livremente pactuadas, a legalidade dos juros remuneratórios cobrados superiores a $12 \%$ ao ano, da capitalização e da comissão de permanência. Também apelou contra a repetição do indébito, à antecipação de tutela e os ônus sucumbenciais.

$\mathrm{O}$ apelo foi julgado parcialmente procedente pela Terceira Câmera de Direito Comercial, autorizando a manutenção da 
taxa de juros remuneratórios, nos termos em que foi pactuada; permitir a incidência da capitalização dos juros como foi contratada; revogar a antecipação da tutela e distribuir os ônus sucumbenciais entre os litigantes.

O Desembargador Revisor Paulo Roberto Camargo Costa refuta o que foi arguido pela instituição bancária, sobre a impossibilidade de revisão das cláusulas contratuais, explanando sobre a função social do contratado, colacionando-se a explicação:

[...] Essa possibilidade de revisão dos contratos se insere nos princípios também consagrados pelo Código Civil vigente, de condicionar a liberdade de contratar "em razão e nos limites da função social do contrato", obrigando que os contratantes guardem, "assim na conclusão do contrato, como em sua execução, os princípios de probidade e boa-fé" (arts. 421 e 422).

Tal visão não é nova na Doutrina e na própria Legislação Brasileira, pois, como já observava VICENTE RAO, "a ordem econômica contemporânea, caracterizada pelo progresso das ciências aplicadas e da técnica, com suas conseqüentes concentrações de capitais, a produção em massa dos bens de consumo e correlativos problemas do trabalho, bem assim o fenômeno das grandes aglomerações urbanas e, ainda, os abusos do mercado monetário, criaram ou acentuaram situações de desigualdade condenadas pela justiça distributiva, por prejudiciais ao equilíbrio social. Daí a legislação especial que veio amparar, preventiva e repressivamente, a situação econômica dos consumidores, trabalhadores, locatários, devedores, etc., vedando ou impondo limites a certas vantagens econômicas dos produtores, vendedores, patrões, locadores, credores, etc. Mas, essas leis proibitivas ou restritivas nem sempre dizem respeito ao conflito entre os elementos volitivos e a declaração, isto é, nem sempre partem do pressuposto da existência de um contraste entre a vontade real e a vontade declarada nos casos de violação de seu preceitos: o conflito 
ou contraste se caracteriza, juridicamente, dentro da autonomia normal da vontade, segundo as circunstâncias de cada caso concreto, ao passo que a acenada legislação protetora preestabelece limitações especiais a serem, necessariamente, observadas na celebração de determinados contratos, sob pena de invalidade das declarações de vontade que as infringem"(SANTA CATARINA, 2012).

A nova ordem econômica implica em condicionar a liberdade de contratar e ocorrendo fatos supervenientes que rompam com a comutatividade do contrato, ou a presença de cláusulas que fixem obrigações desproporcionais, a ponto de se tornar extremamente onerosa para uma das partes, a revisão contratual mostra-se admissível. Desta forma, não há violação do pacta sunt servanda, mesmo que se tenha a revisão contratual.

Diante do caso, verifica-se que a flexibilização do pacta sunt servanda ocorreu pelo princípio da onerosidade excessiva e da função social do contrato.

Em igual entendimento foi proferido decisão na Apelação Cível n²013.040101-3, a saber:

APELAÇÃO CÍVEL. REVISIONAL DE CONTRATO. CÉDULA DE CRÉDITO BANCÁRIO. SENTENÇA QUE JULGA PARCIALMENTE PROCEDENTES OS PEDIDOS VAZADOS NO PÓRTICO INAU. GURAL. INSURGÊNCIA PARCIAL DO CONSUMIDOR.

$[\ldots]$

CÓDIGO DE DEFESA DO CONSUMIDOR. INCIDÊNCIA. EXEGESE DA SÚMULA 297 DO SUPERIOR TRIBUNAL DE JUSTIÇA. PRINCÍPIOS DO PACTA SUNT SERVANDA E AUTONOMIA DA VONTADE QUE CEDEM ESPAÇO, POR SEREM GENÉRICOS, À NORMA ESPECÍFICA DO ART. 6, INCISO V, DA LEI 8.078/90. POSSIBILIDADE DE REVISÃO DO CONTRATO, NOS LIMITES DO PEDIDO 
DO DEVEDOR. INTELIGÊNCIA DOS ARTS.

2。, 128, 460 E 515, TODOS DO CÓDIGO DE PROCESSO CIVIL (SANTA CATARINA, 2013).

No corpo do Acórdão observa-se a possibilidade de se rever as cláusulas contratuais que forem abusivas ou que coloquem o consumidor em situação desfavorável de acordo com o preceito do rebus sic stantibus. Segundo o art. 51, inciso IV, da Lei8.078/90, a revisão contratual não viola o princípio do pacta sunt servanda e também não viola o princípio da autonomia da vontade que, por serem genéricos, cedem espaço a norma específica do art. $6^{\circ}$, inciso V do CDC, somente há a flexibilização de tal preceito para que se atinja a função social do contrato.

O julgado ainda ressalta que a viabilidade de modificação das cláusulas pelo juiz não significa que a tarefa possa de ser feita de ofício, conforme os artigos $2^{\circ}, 128,460$ e 515, todos do Código de Processo Civil (CPC). Tem que haver a provocação do juiz para que o mesmo possa analisar as cláusulas. Se, ao magistrado couber a análise da validade das cláusulas contratuais sem que as partes o provoquem e foras das hipóteses legais, seria permitir que ele atuasse como procurador de uma das partes, o que não é concebível pelo CPC.

Assim, a revisão contratual e a flexibilização da autonomia da vontade podem ser feitas, desde que provocado o juiz, que se aponte o que supostamente se tornou abusivo.

Ainda, colhe-se do Tribunal de Justiça do Estado de Santa Catarina:

AC̣ÃO REVISIONAL DE CONTRATO DE FINANCIAMENTO COM GARANTIA DE ALIENAÇÃO FIDUCIÁRIA.

CLÁUSULAS PREESTABELECIDAS PELA INSTITUIÇÃO FINANCEIRA. EXEGESE DO ART. 54 DO CDC. PACTO DE ADESÃO CONFIGURADO. RELATIVIZAÇÃO DO PRINCÍPIO DO PACTA SUNT SERVANDA. APLICAÇÃO DO ART. $6^{\circ}, \mathrm{V}$, DO CDC. POSSIBILIDADE. 
(Ap. Cível n. 2010.050520-2, de Timbó, rel. Des. Jorge Luiz de Borba, j. em 14/12/2010)(SANTA CATARINA, 2010).

A lei $\mathrm{n}^{\circ}, 8.078 / 90$ (Código de Defesa do Consumidor CDC), em seu capítulo VI, estabelece algumas regras com o intuito de controlar a liberdade contratual e de impedir eventuais abusos. Aqui, leva-se em consideração que a maioridade das cláusulas pactuadas nos contratos bancários são estipulas pelas próprias instituições bancárias.

A partir das estipulação do art. $6^{\circ}$ do CDC, a regra geral do CPC, que após firmado o contrato há a vinculação entre as partes e o negócio jurídico, é relativizada, especialmente no que tange aos contratos bancários, flexibilidade o pacta sunt servanda e admitindo a revisão contratual.

O intuito da flexibilização não é de se modificar livremente as cláusulas e de se excluir a autonomia da vontade, mas de resguardar a função social do contrato e a boa-fé objetiva, com o objetivo de se manter o equilíbrio contratual.

Extrai-se da doutrina da Cláudia Marques (2004, p. 766):

O Código de Defesa do Consumidor inova consideravelmente o espírito do direito das obrigações, e relativa à máxima pacta sunt servanda.

A nova lei vale reduzir o espaço antes reservado para autonomia de vontade, proibindo que se pactuem determinadas cláusulas, vai impor normas imperativas, que visam proteger o consumidor, reequilibrando o contrato, garantindo as legítimas expectativas que depositou no vínculo contratual.

A proteção do consumidor, o reequilíbrio contratual vem a posteriori, quando o contrato já está perfeito formalmente, quando o consumidor já manifestou sua vontade, livre e refletida, mas o resultado contratual ainda está inequiquativo. As normas proibitórias de cláusulas abusivas são normas de ordem pública, normas imperativas e inafastáveis pela vontade das partes. Estas normas do CDC aparecem 
como instrumento do direito para restabelecer o equilíbrio, para restabelecer a força da vontade, das expectativas legítimas, do consumidor, compensando, assim, sua vulnerabilidade fática.

Pelo exposto, a revisão contratual que tem como base o princípio pacta sunt servanda visa a proteger o consumidor e o reequilíbrio da relação obrigacional existente mantendo o vínculo contratual existente.

Em julgado do Tribunal de Justiça do Rio Grande do Sul, Apelação Cível n 70053694014, o relator disserta sobre a sobreposição do princípio do pacta sunt servanda a outros princípios da escola clássica:

APELAÇÕES CÍVEIS. AÇÃO REVISIONAL DE CONTRATO DE CÉDULA DE CRÉDITO BANCÁRIO GARANTIDO COM CLÁUSULA DE ALIENAÇÃO FIDUCIÁRIA.

$[\ldots]$

INCIDÊNCIA DO CÓDIGO DE DEFESA DO CONSUMIDOR. O crédito fornecido ao consumidor/pessoa física para utilização na aquisição de bens no mercado como destinatário final se caracteriza como produto, importando no reconhecimento da instituição bancária/financeira como fornecedora para fins de aplicação do CDC, nos termos do art. $3^{\circ}$, parágrafo $2^{\circ}$, da Lei no 8.078/90. Entendimento referendado pela Súmula 297 do STJ.

DIREITO DO CONSUMIDOR À REVISÃO CONTRATUAL. $\mathrm{O}$ art. $6^{\circ}$, inciso $\mathrm{V}$, da Lei $\mathrm{n}^{\circ}$ 8.078/90 instituiu o princípio da função social dos contratos, relativizando o rigor do "Pacta Sunt Servanda" e permitindo ao consumidor a revisão do contrato, especialmente, quando o fornecedor insere unilateralmente nas cláusulas gerais do contrato de adesão obrigações claramente excessivas, suportadas exclusivamente pelo consumidor, como no caso concreto. 
PRELIMINAR REJEITADA.

\section{APELAÇÃO DO AUTOR IMPROVIDA E APELAÇÃO DO RÉU PROVIDA EM PARTE (RIO GRANDE DO SUL, 2013).}

No julgado em questão, o autor ingressa com ação de revisão de contrato bancário garantido com cláusula de alienação fiduciária. A ação foi julgada parcialmente procedente para os pedidos de: a) afastar a incidência da comissão de permanência; b) limitar os juros remuneratórios à taxa média do mercado, ou à taxa pactuada (a que for mais benéfica ao consumidor); e c) ordenar a dedução dos valores a serem restituídos do saldo devido pelo autor da demanda e, no caso de compensação dos valores a verificação do crédito em favor deste, deverão ser devolvidos com acréscimo de juros e correção monetária.

Devido a decisão proferida pelo juiz em primeira instância, as partes interpuseram o recurso de apelação civil. $\bigcirc$ tribunal julgou pelo provimento parcial do impugnado pela instituição bancária e a rejeição do que foi impugnado pelo autor.

Extrai-se do corpo do acordão a explanação sucinta da relatora sobre o principio do pacta sunt servanda:

Estando o contrato sub judice sujeito ao CDC, terá o consumidor o direito de revisar seus termos que entender ilegais ou abusivos.

Em se tratando de contrato de adesão, resta claro que a única opção do autor, no que se refere às cláusulas estabelecidas, diz respeito somente entre sua aceitação ou não em relação ao conteúdo do contrato, sendo certo que este não possui nenhuma ingerência sobre sua elaboração, restando-lhe somente a opção entre aderir ou não às condições ali elencadas.

Ademais, a revisão poderá ocorrer em virtude da mitigação do princípio da "Pacta Sunt Servanda", para que seja evitada a onerosidade excessiva. 
Nesse raciocínio, temos o art. 51, inciso IV do CDC, que determina a nulidade das cláusulas contratuais que estabeleçam obrigações consideradas abusivas ou incompativeis com a boa-fé.

Deve-se ressaltar que não se está negando vigência ao princípio do Pacta Sunt Servanda, que faz lei entre as partes, mas somente afastá-lo em relação às cláusulas abusivas, ou seja, as que geraram a situação de desequilíbrio entre as partes.

Portanto, prevalece, atualmente, o princípio da relatividade do contrato, como forma de assegurar o equilíbrio da relação contratual (RIO GRANDE DO SUL, 2013).

Percebe-se pelo exposto que o consumidor pode revisar o contrato quando entender que seus termos são abusivos ou ilegais. Mais enfatizado ainda a possibilidade de se rever o contrato quando este for de adesão pois ao consumidor não é dado oportunidade de se manifestar a certa do conteúdo do contrato, cabendo a ele somente aderir ou não o que lhe foi imposto.

Ainda, a relatora ressalva que o principio do pacta sunt servanda é flexibilizado neste momento em deprimente ao princípio da boa-fé. Aquele é afastado no que tange ao que for abusivo, ilegal, e ao que causar desequilíbrio entre as parte, mantendo-se o vinculo entre os contratantes porém de forma mais justa. No que for possível a relação se manterá incólume buscando-se a relação justa e sadia.

Destaca-se que cada tribunal tem um entendimento do que é abusivo e do que causa a flexibilização do referido princípio, cabendo ao magistrado proferir a decisão de acordo com o caso em concreto e de acordo com o que for mais justo para as partes.

Em sua maioria, as irresignações tinham por fundamento a taxa de juros remuneratórios praticadas pelas instituições financeiras. $\mathrm{O}$ procedimento adotado era a limitação dos juros 
à taxa média do mercado (numeral simbólico disponibilizado pelo Banco Central do Brasil), em boa parte da jurisprudência pátria sem o intuito de prover munição aos tribunais a serem deflagradas nas ações revisionais.

Percebe-se que a liberalidade da autonomia da vontade, do individualismo e a limitação da intervenção estatal nas relações privadas foram alteradas, primando-se pelo equilíbrio da relação contratual entre as partes. A elevação dos acordos à categoria de leis (o que ocasionava a obrigação das partes em cumprirem com o contratado pelo principio do pacta sunt servanda) está relativizado pela possibilidade de revisão contratual frente a abusos e ilegalidades.

\section{CONCLUSÃO}

A cada dia, novas interpretações para os institutos contratuais são desenvolvidas, oferecendo suporte ao mercado em formação. Atualmente, as partes, de um modo geral, contam com mais uma segurança jurídica na realização de um novo contrato, que visa não somente permitir a expansão econômica, mas também para possibilitar a queda de barreiras comerciais, importante motor da globalização.

Com o aumento das relações comercias nasce a necessidade de se adequar a Lei contratual a essas novas situações. A flexibilização do pacta sunt servanda foi uma das modificações realizadas pelo legislador com o intuito de possibilitar a revisão de uma relação comercial desequilibrada, que antes não se vislumbrava. Essa flexibilização foi amparada pela jurisprudência brasileira, que adequou a regulamentação dada pela Código Civil à realidade, utilizando como base princípio contratuais, como o da função social do contrato, princípio da boa-fé, combinando-os com a teoria da imprevisão (ou Princípio da Revisão dos Contratos).

A possibilidade de ser rever a relação negocial, com a intervenção judicial, não deve ser visto como uma forma de 
se extinguir o vínculo existente entre as partes, mas adequá-lo, tornando-o possível de ser adimplido.

Em rigor, as disposições legais referentes à flexibilização do pacta sunt servanda servirão de base para a perpetuação do vínculo contratual existente, aquedando-o, somente, à realidade vivenciada pelo país.

Observa-se que a liberdade de contratar permanece inalterada, mas há o direcionamento com o intuito de se preservar o bem-estar social e a função social do contrato. O Estado sempre terá que observar, nas intervenções, os interesses comuns e coletivos e a igualdade de direitos, revendo o contrato para que esses direitos sejam observados e preservando o vínculo existente entre as partes, tornando-o mais justo.

Abstract: This paper focuses on the flexibility of pacta sunt servanda in banking contracts before the contractual dirigisme, represented by the principles of the social function of the contract principle of good faith and theory of unpredictability. This research aims to analyze the importance of flexibility of pacta sunt servanda in banking contracts against other principles protected by homeland law. Regarding the methodology used to develop the study, it was defined as a deductive technique and literature review approach. The paper is organized as follows: first comes to banking contracts and after incursion on contractual principles and finally the flexibility of pacta sunt servanda in banking contracts. As a result, it is observed that the jurisprudence searched the main reason for the easing of bank contracts is the application of the theory of unpredictability, in addition to safeguarding the social function of contract and good faith in cases of contractual review.

Keywords: Bank Contracts. Contract law. Jurisprudence. Pacta Sunt Servanda. 


\section{REFERÊNCIAS}

ALMEIDA, João Batista de. A proteção Jurídica do Consumidor. 7 ed. São Paulo: Saraiva, 2009.

BANDEIRA DE MELLO, Celso Antônio. Curso de direito administrativo. 19. ed. SP: Malheiros , 2005

BELMONTE, Cláudio. Proteção contratual do consumidor: conservação e redução do negócio jurídico no Brasil e em Portugal. São Paulo: Revista dos Tribunais, 2002.

BRASIL. Código Civil de 2002. Disponível em: <http://www.planalto.gov. br/ccivil_03/leis/2002/110406.htm>. Acesso em: 20/08/2013.

. Código de Defesa do Consumidor - Lei no 8.078/90. Disponível em: <http://www.planalto.gov.br/ccivil_03/leis/18078.htm>. Acesso em: 13/09/2013.

COElHO, Fábio Ulhoa. Curso de Direito Civil 3: contratos. $4^{\circ}$ ed. São Paulo: Saraiva, 2010.

DALLAGNOL, Deltan Martinazzo. Contratos bancários: conceito, classificação e características. Disponível em < http://jus.com.br/ artigos/3262/contratos-bancarios $>$ Acesso em 11/12/2013.

DINIZ, Maria Helena. Curso de direito civil brasileiro: teoria das obrigações contratuais e extracontratuais. 29 ed. São Paulo: Saraiva, 2012.

GAGLIANO, Pablo Stolze; PAMPLONA FILHO, Rodolfo. Novo curso de direito civil: contratos - contratos. 11 ed. São Paulo: Saraiva, 2009.

GOMES, Orlando. Contratos. 26 ed. rev. atual. Rio de Janeiro: Forense, 2007.

GONÇALVES, Carlos Roberto. Direito Civil Brasileiro, volume 3:

Contratos e Atos Unilaterais. 7 ed. São Paulo: Saraiva, 2010.

LISBOA, Roberto Senise. Manual de Direito Civil: contratos e declarações unilaterais - teoria geral e espécies. 3 ed. São Paulo: RT, 2005.

LUZ, Aramy Dornelles da. Negócios jurídicos bancários, o banco múltiplo e seus contratos. Revista dos Tribunais, São Paulo, 1996.

MARQUES, Cláudia. Contratos no código de defesa do consumidor: o novo regime das relações contratuais. 4.ed., São Paulo: Revista dos Tribunais, 2004.

Contratos no Código de Defesa do Consumidor: o novo regime das relações contratuais. 6 ed. São Paulo: RT, 2011 
MATO GROSSO. Tribunal de Jusitça. Apelação Cível no 60286/2010. Relator Des. Sebastião de Morais Filho. 25 de ago. 2010. Disponível em <http://servicos.tjmt.jus.br/processos/tribunal/dadosProcesso.aspx>. Acesso em: 20/08/2013.

MIRANDA, Maria Bernadete. Contratos Bancários. Disponível em: < http://www.direitobrasil.adv.br/arquivospdf/revista/revistav22/aulas/ cb.pdf >. Acesso em: 30 set. 2013.

MONTEIRO, Washington de Barros; MALUF, Carlos Alberto Dabus; SILVA, Regina, Beatriz Tavares da. Direito das Obrigações - $2^{\circ}$ parte. 39 ed. São Paulo: Saraiva, 2012.

RIO GRANDE DO SUL. Tribunal de Jusitça. Apelação Cível no 70053694014. Relator Desa. Vanderlei Teresinha T. Kubiak. 09 de maio 2013 Disponível em <http://www1.tjrs.jus.br/site_php/consulta/ consulta_processo.phpnome_comarca $=$ Tribunal $+\mathrm{de}+\mathrm{Justi} \% \mathrm{E} 7 \mathrm{Q} \&$ vers $\mathrm{ao}=\& v e r s a o \_$fonetica $=1 \&$ tipo $=1 \&$ id_comarca $=700 \&$ num_processo_ mask $=70053694014 \&$ num_processo $=70053694014 \&$ codEmenta $=5251532$ \& temIntTeor=true>. Acesso em 14/08/2013

RIZZARDO, Arnaldo. Contratos. 6 ed. Rio de Janeiro: Forense, 2006.

Forense, 2010. . Contratos. $6^{\circ}$ ed. $2^{\circ}$ tiragem. Rio de Janeiro:

SANTA CATARINA. Tribunal de Jusitça. Apelação Cível nº 2012.081040-8. Relator Des. Paulo Roberto Camargo Costa . 08 de ago de 2013. Disponível em <http://app6.tjsc.jus.br/cposg/ pcpoQuestConvPDFframeset.jsp?cdProcesso $=01000$ NDRW0000\& nuSeqPr ocessoMv=22\& tipoDocumento=D\&nuDocumento=5916710 >. Acesso em: 20/08/2013

Tribunal de Justiça. Apelação Cível no 2013.040101-3. Relator Des. José Carlos Carstens Köhler. 13 ago de 2013. Disponível em <http://app6.tjsc.jus.br/cposg/pcpoQuestConvPDFframeset.jsp?cdProcess $\mathrm{o}=01000 \mathrm{P} 1 \mathrm{VQ} 0000 \&$ nuSeqProcessoMv=44\& tipoDocumento=D\& nuDoc umento $=5929772>$. Acesso em: 30/08/2013

THEODORO JÚNIOR, Humberto. O contrato e sua função social. Rio de Janeiro: Forense, 2004.

VALÉRIO, Fabiana Borges. Teoria da imprevisão enfoque nos contratos de locação de coisas. Disponível em: <http://arquivo.fmu.br/prodisc/direito/ fbv.pdf>. Acesso em: 06 jun. 2012.

VENOSA, Sílvio de Salvo. Direito civl: teoria geral das obrigações e teoria geral dos contratos. 12 ed. São Paulo: Atlas, 2012.

WALD, Arnoldo. Obrigações e Contratos. 16 ed. São Paulo: Saraiva, 2004. 